psychiatric reactions to gabapentin and only one other report of hypomania.

The drug company advises daily incremental doses until the patient is on a minimum maintenance dose. We suggest that this advice be viewed more cautiously in patients with a past psychiatric history of mood disorder or psychotic disturbance.

C. SHORT

L. COOKE

Stoke Park Hospital

Bristol BS16 1QU

\section{Schizophreniform psychosis after stage hypnosis}

SIR: I wish to report a case of schizophreniform psychosis which developed in a man with no previous psychiatric history after he was the subject of stage hypnosis.

A 25-year-old man attended a performance by a well-known stage hypnotist. He volunteered for hypnosis and 'performed' in front of the audience. The next day his girlfriend described him as 'giggly' at a meeting at work where the possibility of redundancy was being discussed. He complained of headaches. A day later at the theatre he laughed inappropriately throughout the show and over the next three days he developed auditory hallucinations and believed that he was being told what to do. He became very frightened and believed that he was going to die and became quite angry and verbally aggressive towards his girlfriend. He began to emulate his girlfriend's movements and would not let her out of his sight. He had ideas of reference, for example believing that blinking meant something significant to him.

He was admitted informally to an acute psychiatric ward nine days after the stage show. History revealed no evidence of past psychiatric illness. Mental state examination at the time showed evidence of paranoid ideation, ideas of reference and auditory hallucinations in the second person. A diagnosis of an acute schizophrenic episode was made and he was treated with chlorpromazine $100 \mathrm{mg}$ t.d.s. reducing to $150 \mathrm{mg}$ daily over a 3 week period.

He was followed up by a community psychiatric nurse and in the out-patient department where he made a slow recovery, and his medication was tailed off over a period of six months. However, he continued to be very wary about what he watched on television and he described feelings of foreboding on walking past churches. Two months later he had become increasingly perplexed and his chlorpromazine was restarted. Shortly after this he saw a show on television featuring the same stage hypnotist who had hypnotised him and he became quite paranoid, believing that the behaviour of characters in a television soap opera were giving him messages by their behaviour and reading significance into the numbers in the lottery which he felt related in some way to the 'count' after his hypnosis. He was treated with increased doses of chlorpromazine.

Although the psychiatric literature is replete with references to hypnotherapy being used as a treatment for psychosis I could find no record of hypnosis as a precipitant of a psychotic illness. Nevertheless there is evidence that stage hypnosis can lead to a number of subjective negative experiences for participants after the event (Crawford et al, 1992). Just over one-third of respondents in this study reported mild to strong negative experiences including being frightened and confused.

According to the Health \& Safety Executive (Lucas, personal communication) "subjecting sensitive/paranoid individuals to ridicule" can lead to "adverse effects".

In this patient's case it is likely that stage hypnosis was the significant life event which triggered a schizophrenic illness. Clearly there are lessons to be learnt by stage hypnotists about the potentially serious outcome for a very small minority of participants in what is supposed to be a form of entertainment.

\footnotetext{
Crawford, H. J., KItNer-Triolo, M., Clarke, S. W., et al (1992)

Transient positive and negative experiences accompanying stage hypnosis. Journal of Abnormal Psychology, 101, 663-667.

Frischrolz, E. J., Lipman, L. S., Braun, B. G., et al (1992)

Psychopathology, hypnotizability and dissociation. American Journal of Psychiatry, 149, 1521-1525.
}

North Wycombe C.M.H.T.

D. S. Allen

\section{Cedar Avenue}

Hazlemere

High Wycombe

Bucks. HP15 7DW

\section{Nietzsche, Freud and eternal recurrence of the repressed ...}

SIR: I read Chapman \& Chapman-Santana's paper on the influence of Nietzsche on Freud's ideas with interest (BJP, February 1995, 166, 251-253). I was, however, rather disappointed that the authors mention only fleetingly the pivotal achievement of Nietzschean thought - the eternal recurrence - and make no connection between this and the cardinal Freudian idea of 'repetition compulsion'. In Beyond Good and Evil Nietzsche translates Zarathustra's 